\title{
O SORRISO INSUPORTÁVEL DE BARTLEBY, SEGUNDO SLAVOJ ZIZEK
}

\author{
Fernando Facó de Assis Fonseca ${ }^{1}$
}

\section{Resumo:}

O preferiria melhor não de Bartleby, essa recusa insistente e compulsiva, faz do personagem um verdadeiro revolucionário. Esta rejeição disciplinar não é uma resistência estetizante que o mantém puro e afastado do jogo burocrático; jogo que contamina o ambiente com transações corruptas etc. Esta rejeição expressa um gesto puro e vazio que, em vez de permanecer imaculado, é ele que contamina o sistema em questão. Bartleby é revolucionário porque sua violência reside, não no espaço interno da ordem estabelecida, mas sim na Lei que determina a coerência interna do sistema. O presente trabalho pretende mostrar como é possível reverter a lógica dominante do mundo pós-ideológico por um gesto similar à rejeição bartleblyniana proposta por Zizek.

Palavras chaves: Pós-modernismo, Bartleby, Ato político

\begin{abstract}
:
Bartleby's I would prefer not to, an insistent and compulsive refusal, makes the character a true revolutionary. This disciplinary denial is not an aestheticizing resistance that keeps him pure and away from the bureaucratic game that contaminates the environment with corrupted transactions etc. This rejection expresses a pure and empty gesture which instead of remain immaculate contaminates the system in question. Bartleby is revolutionary because his violence lies not in the internal space of the established order, but in the law which determines the internal coherence of the system. The present work aims at showing how it is possible to reverse the dominant logic of the post-ideological world for a gesture which is similar to the bartleblyan rejection proposed by Zizek.
\end{abstract}

Keywords: Postmodernism, Bartleby, Political act.

\section{Introdução}

A década de noventa foi um período extremamente fértil para que pensadores em geral ensaiassem modelos teóricos capazes de não apenas compreender, mas acima de tudo prever as direções de novas formas políticas com as quais o mundo teria de lidar num futuro próximo. A causa óbvia disto era o momento crucial que a história

\footnotetext{
${ }^{1}$ Doutorando em Educação pela Universidade Federal do Ceará (UFC), vinculado ao eixo Filosofia, Política e Educação. Bolsista CAPES. E-mail: fernandofaco@ hotmail.com.
} 
atravessava com o fim do comunismo e a dissolução do bloco soviético. Em proporções razoáveis de medo e esperança, deu-se início, portanto, a uma nova era da política mundial, na qual novos contornos teóricos teriam de ser delineados a fim de esclarecer e conduzir por uma lógica discernível os acontecimentos que alteravam a ordem estabelecida. É nesse contexto que surgem, por exemplo, pensadores como Francis Fukuyama (1992) e Samuel Huntington (2010), propondo, cada um ao seu modo, uma nova compreensão da política no fim do século XX.

Deste modo, enquanto, por um lado, Fukuyama (1992) argumentava que a fórmula final da melhor ordem social possível foi encontrada no modelo de democracia liberal capitalista, pois não havia mais nenhum formato conceitual mais avançado, somente obstáculos empíricos a ultrapassar; Huntington (2010), por sua vez, alegava que o mundo se organizaria não mais a partir de fatores ideológicos, políticos ou econômicos, mas por meio de fatores essencialmente culturais. De um lado, temos, com Fukuyama, o fim da história, enquanto, de outro, com Huntington, a historia continua, no entanto, compreendida em termos de choques entres civilizações. O que aparentemente pode ser interpretado enquanto visões teóricas divergentes, não passa na verdade de uma única e mesma leitura do mundo pós-guerra: o choque entre civilizações é em ultima instância o fim da historia, na exata medida em que a nova ordem estabelecida é considerada, por ambos os pensadores, como sendo fundamentalmente pós-ideológica. Talvez, o que Huntington não enxergue é que lutas entre culturas não são capazes de conduzir o espírito histórico no sentido em que este foi erguido e mantido por ideais revolucionários e propostas transformadoras. Por isso, nessa concepção apocalíptica, o significado mais profundo de história se encontra terminantemente morto, já que fora desprovido de sua mola propulsora. (E, diga-se de passagem, esse aspecto pós-ideológico da política é fator tão incontestavelmente aceito para grande parte do pensamento contemporâneo, que isto é tomado, de antemão, como algo dado e evidente.) Em suma, a perda do conteúdo ideológico da realidade implica consigo o estágio final e conclusivo da história.

Consequentemente, a opinião geral em nossa época pós-moderna preconiza que a realidade na qual vivemos se apresenta rigorosamente na sua forma efetiva e não mais ideológica. O que em outros termos significa que, a um passo de alcançar os pressupostos básicos da razão iluminista, este momento consiste no tão esperado momento da emancipação humana. Nesse sentido, diante de tal perspectiva, qualquer que seja a crença ou luta por ideais renovadores e revolucionários torna-se, por assim 
dizer, anacrônico em relação ao que se configura como a nova ordem política e a forma como se organiza seu estado de coisas vigente. Não admitindo, pois, mais discursos ideológicos/universais, essa nova configuração da política funda, portanto, aquilo que Zizek (2011) denomina de pensamento fraco: discursos cujas grandes causas padecem de maneira inexorável. De forma irônica, diz ele que a:

(...) era das grandes explicações acabou, precisamos de um pensamento 'fraco', oposto a todo fundamentalismo, um pensamento atento à textura rizomática da realidade; também na política, não deveríamos mais visar os sistemas que tudo explicam e os projetos de emancipação global (ZIZEK, 2011, p. 20).

A ideia de democracia regente no mundo contemporâneo se apresenta, em última instância, como a alternativa mais bem elaborada de regime político após a desintegração do bloco soviético. De maneira que, numa curiosa análise, a democracia surge como uma escolha deliberada feita pelo ocidente após ter amargamente experimentado regimes como o fascismo, o socialismo e, não esquecer, a monarquia. O que nos deixa a estranha impressão, como já sugerira Adorno (1995), de que no fundo estamos diante de um cardápio de sistemas políticos no qual a democracia aparece como uma espécie de prato do dia, mais em conta e mais prático. Uma rápida análise da história revela, porém, que a democracia, tal como a conhecemos, não é de modo algum o resultado de lutas sangrentas por uma idônea maioridade moral da espécie humana, isto é, um regime que se empenha em buscar uma integração maior da classe oprimida etc.; essa democracia com a qual lidamos é simplesmente um modelo prêt-à-porter, o que melhor convém ao sistema econômico capitalista. A democracia liberal multiculturalista não é outra coisa senão um comovente apelo imposto pela nova etapa do sistema capitalista mundial enquanto work proposition.

É particularmente nesse contexto que a política se revela desprovida de seu núcleo duro - ideológico e passional - para se consumar enquanto ideia paradoxal de um sistema político sem política, e cuja contradição inerente é o que melhor exprime nossa lânguida era pós-política. A pós-política, como propôs Jacques Rancière,

(...) insiste no fato de que é necessário deixar para trás as velhas divisões ideológicas para enfrentar os novos problemas 'globais', se armando de especialistas indispensáveis e do livre discurso que leva em conta as necessidades e as reivindicações de todos" (apud ZIZEK, 2002, p.34).

Em outros termos, a pós-política fica assim reduzida particularmente a um gênero de administração de problemas sociais, que compõe o quadro desde sempre préestabelecido das relações sociopolíticas existentes. Isso é o mesmo que dizer que a política pós-moderna não se ocupa senão em cumprir certas regras administrativas já 
pressupostas por um campo determinado de execuções protocolares, deixando totalmente de lado seu aspecto criador e revolucionário. Quando isto acontece, o preço a pagar é justamente a perda da política ela mesma, ou seja, enquanto regimento administrativo e burocrático, ela é esvaziada de seu eixo substancial mais elementar, aquele $\mathrm{X}$ insondável que traduz todo e qualquer movimento político em política propriamente dita.

A consequência inevitável da despolitização da esfera econômica é, com efeito, o triste desvio que transforma toda discussão ativa, sobre tomada de decisões coletivas e responsáveis, em problemas administrativos gerais. Tal efeito produz na maioria das vezes um gênero específico de debate concentrado particularmente em minorias culturais, em que serão basicamente as diferenças sexuais, étnicas e religiosas que ocuparão a frente do cenário político; enquanto as decisões mais fundamentais e transformadoras do ponto de vista da maioria social ficam reduzidas para segundo plano. As democracias neoliberais, cujo efeito mais nefasto é esse vazio político universalmente compartilhado, é portanto o modo de ser do nosso mundo pós- ideológico/multiculturalista. $\mathrm{O}$ dilema aqui reside no fato de que o desaparecimento do fundamento político na pós-política consiste na condição sine qua non que garante as nossas pseudoliberdades individuais, de modo que, tanto o direito à privacidade, como a liberdade de expressão e a crença religiosa só são, com efeito, possíveis na medida em que o Estado não interfira no livre curso da economia. Isto significa, mais precisamente, que nossa ideia de democracia é fundamento incondicional do capitalismo e, por tal razão, um posicionamento genuinamente político revelar-se-ia tão pouco provável nos dias de hoje que, em certo aspecto, é muito mais fácil aceitar uma catástrofe natural de proporções colossais, que, efetivamente, conceber o fim do capitalismo. Assim, não é possível empreender mudanças reais no cenário político sem abdicar minimamente do espaço simbólico que garante as coordenadas elementares do jogo político contemporâneo - incluindo nele todas as liberdades com as quais estamos familiarmente acomodados. Para dizer as coisas de modo simples e preciso, a ideia central aqui consiste em que, para rompermos com a raiz do sistema capitalista é igualmente necessário que se renuncie aos ícones supremos do marketing da democracia liberal, isto é, o posto que ocupamos enquanto indivíduos (pseudo)livres e (pseudo)autônomos.

Nessas condições, o capitalismo revela-se, por definição, um sistema praticamente indestrutível: indestrutível, à medida que os partidos políticos ditos de 
resistência se limitam a combatê-lo, por assim dizer, no horizonte de capitalismo mais humano, isto é; na medida em que se limitam em confrontar os aspectos mais degradantes do capitalismo sem de fato privar-se do efeito (pseudo)democrático que ele oferece. Nessa perspectiva, Zizek (2002) apresenta dois esquemas segundo os quais nossa política de resistência se enquadra perfeitamente. Diante dessa aparente inexorabilidade do capitalismo: ou bem insistimos em um gesto vazio e inexpressivo de fidelidade a um conteúdo ideológico obsoleto, de modo que, quando não há mais esperanças para lutar, restam apenas princípios a seguir (assim como os famosos comícios de esquerda que são na verdade percebidos muito mais como algo bizarro e antiquado do que seriamente ameaçadores); ou, por uma tentativa de adequação ao estado de coisas vigente, depõemse as armas e institui-se, a conta gotas, alguns antigos valores que, sob certa medida, não causam maiores danos à lógica triunfante do sistema atual. Consequentemente, a esquerda hoje em dia aparenta, no melhor dos casos, a uma grande mosca varejeira que causa evidentemente certa repugnância, mas que, como todos sabem, não chega a picar.

Diante desse plano lúgubre, um problema urgente se apresenta: não se trata aqui de defender um puro e simples retorno às velhas ideias de luta de classes e revolução comunista, mas, mais precisamente, de saber como é verdadeiramente possível minar o sistema capitalista mundial de forma efetiva e sem retórica (ZIZEK, 2002).

Uma saída possível pode ser articulada por meio da ideia de política de subtração proposta por Alain Badiou (ZIZEK, 2011). Por esse viés não há a mínima necessidade de um derreamento de sangue num engajamento brutal pela tomada de poder, a fim de promover mudanças significativas no atual estado de coisas. De modo demasiado singular, essa política não é propriamente destrutiva, antagônica, nem mesmo militarizada. Mediante um gênero de revolução passiva - que, embora passiva, não deixa de ser violenta - essa política não tem como alvo o centro do poder administrativo, tampouco tem o propósito de destituir líderes governamentais específicos: a grande revolução é realizada fundamentalmente no registro simbólico - campo responsável pelas coordenadas que determinam o aspecto constatativo e coeso da realidade. Em outras palavras, a ideia de subtração revolucionaria aqui em jogo tem como tarefa atuar diretamente no próprio quadro categorial que determina a coerência interna da esfera intramundana; o jogo dos elementos no interior da forma total. Como diz Zizek (2011, p. 404): “(...) em vez de destruir-negar diretamente o poder dominante, 
permanecendo em seu campo, ela solapa esse mesmo campo, criando um novo espaço positivo".

Todavia, de acordo com Zizek (2011), haverá sempre subtrações e subtrações, isto é, diferentes maneiras de pensar a política de subtração. Podemos, por um lado, pensá-la enquanto uma simples negação que, recusando-se a fazer parte do jogo obsceno da política, contenta-se em exercer uma crítica ininterrupta da realidade por meio de queixas intermináveis sobre as injustiças do mundo. Neste modelo, podemos enquadrar não somente as práticas meditativas new age, adotada por uma legião de executivos do bem (os quais, impregnados das impurezas e dos vícios do sistema capitalista, convertem-se em religiões pseudo-orientais como um modo de recuperar as boas energias do universo); como, também, os intelectuais de esquerda, que preferem permanecer à distância do Estado, sempre promovendo suas críticas de forma ilesa e autônoma.

$\mathrm{Na}$ verdade, essa subtração enquanto simples negação consiste essencialmente na típica atitude da bela alma hegeliana. "Em vez de agir, a Bela Alma fala, exprime suas convicções profundas deplorando o triste estado no mundo, as injustiças etc.; não quer sujar suas mãos, quer manter-se a qualquer preço longe do mundo prosaico" (ZIZEK, 1991, p. 86). Nesse sentido, a bela alma se revela como uma “(...) alma terna, estetizante, requintada demais para a vulgaridade do mundo social” (Idem). Segundo Zizek (1991), essa crítica hegeliana à bela alma não se limita apenas em condená-la por falar e não agir, “(...) por contentar em deplorar o estado do mundo sem nada modificar nele” (Idem). O verdadeiro impasse é que a bela alma é, sob todos os aspectos, profundamente responsável pelo sistema que deplora: tão logo se queixa de sua inadequação estrutural à realidade concreta, “(...) em cujo contexto ela desempenha o papel de vitima passiva", ela simultaneamente engendra as condições efetivas de sua desditosa vida. "A aparência de uma constatação dos fatos dissimula uma cumplicidade, o consentimento ou a vontade ativa de endossar esse papel e, dessa maneira, permitir à situação deplorada que se reproduza" (Idem).

Para facilitar, tomemos como exemplo um célebre personagem da literatura clássica fornecido por Zizek (1991): o da "mãe sofredora”. Essa figura alegórica carrega consigo, num silêncio profundo, o sofrimento de todos os demais membros da família, sacrificando, assim continuamente, sua felicidade pessoal, no intuito de garantir, a duras penas, o bem-estar de seus entes. O que não pode passar despercebido é o papel que cumpre seu sintoma nessa rede intersubjetiva (sintoma este que, decerto, ela ama mais 
do que a ela mesma). Trata-se, com efeito, de manter-se firme nessa posição de vítima, de total anonimato, suportando toda sorte de infortúnio e de padecimento existencial. E por quê? Pelo simples motivo de que, apesar de tudo, a dor circunstancial se torna secundária quando comparada ao gozo narcísico do qual o sujeito usufrui quando inscrito nessa organização simbólica. Em outros termos, o lugar de sacrifício é, a todo rigor, o modo específico segundo o qual a consistência subjetiva da mãe sofredora pode ser minimamente asseverada. E assim, como se o mundo precisasse dela, ela estava disposta a sacrificar tudo, salvo uma única coisa: o próprio sacrifício. Nesse sentido, “(...) o que o sujeito tem que fazer para se livrar de seu papel de 'bela alma' é precisamente esse sacrifício do sacrifício: não basta 'sacrificar tudo', é preciso ainda renunciar à economia subjetiva em que o sacrifício traz o gozo narcísico" (ZIZEK, 1991, p. 86).

Este gesto drástico de renúncia total exigido à bela alma corresponde precisamente à ideia de ato político, segundo Zizek (1991). Em outros termos, para uma real política da subtração, não basta apenas negar o conteúdo contingente e arbitrário, mantendo, assim, intacto o quadro categorial por meio do qual estes elementos são articulados. $\mathrm{O}$ engodo nesta perspectiva da simples negação repousa no fato de que a lei, na sua qualidade puramente formal, permanecerá inalterada, enquanto tudo mais continuará sendo julgado segundo sua máxima. Em oposição a isto, o real efeito político só pode ser cumprido efetivamente se incidirmos diretamente nas próprias coordenadas responsáveis pelo efeito valorativo do sistema, ou seja, nessa própria lei que origina e ordena a coerência interna do espaço simbólico. Como diria Jacques Derrida (2007), a moldura é parte constitutiva da obra: embora estejamos, por assim dizer, automaticamente condicionados a julgar somente a tela, não há, em absoluto, tela sem moldura; uma vez que a segunda dá os contornos e a forma específica da primeira. Esta é a razão pela qual Zizek (2011) insiste em retomar para sua análise política o conceito hegeliano de negação da negação. Segundo este modelo, uma verdadeira mudança política é possível não graças a um simples remanejamento dos elementos situados na esfera intramundana, isto é, interna ao campo do simbólico (simples negação), mas, sobretudo, devido a uma negação que atue na própria eficiência simbólica desse campo (negação da negação).

Por isso, é importante insistir no fato de que um ato político não implica necessariamente num rebuliço incessante na configuração interna do estado de coisas no mundo. Na verdade, tal mudança é no máximo uma simples mudança de olhar sobre 
este mesmo estado de coisas. Se, na primeira negação, permanecemos, de fato, no interior dos limites simbólicos que condicionam meu olhar sobre o mundo; na segunda negação - o que deve vir logo em seguida - é particularmente esse próprio olhar sobre o mundo que deve ser deslocado. O que equivale a dizer que não se trata de transformar o mundo remanejando continuamente de lugar em lugar sua organização interna; o gesto mais fundamental consiste em compreender a lei que determina o estado de coisas no mundo. Deste modo, mudamos completamente de atitude política à medida em que tomamos a própria lei - na sua dimensão propriamente kantiana - como a única transgressão possível, e não especificamente o crime submetido sob o jugo desta lei. Por isso que a verdadeira subtração política é aquela feita na base formal que funda um determinado campo hegemônico, e que somente assim, pode efetivamente intervir nesse campo. É por esta razão que tal subtração é substancialmente violenta: não porque mata sujeitos e destrói monumentos, mas pelo simples fato de afetar violentamente o campo no qual estes elementos estão inscritos, “(...) pondo a nu suas verdadeiras coordenadas” (ZIZEK, 2011, p. 406). A violência maior é, por assim dizer, aquela que age passivamente transformando tudo a seu redor em matéria inerte e insignificante - tal como o terror que se manifesta no olhar impenetrável do condenado que aguarda serenamente e em silêncio sua sentença: o fato é que este já se encontra terminantemente morto na esfera simbólica. Esta é a imagem sombria que exprime nossa verdadeira condição humana; aquela que Zizek (2011) denomina como a condição peculiar do morto-vivo.

É mais ou menos nesse sentido que Zizek (2007) desenvolve uma formidável análise sobre o personagem Bartleby, de Herman Melville. Antes de mais nada, seu exame se opõe radicalmente ao proposto por Michael Hardt \& Antonio Negri (2001). Segundo Zizek (2007), os autores falham ao compreender a recusa de Bartleby - I prefer not to (eu preferiria melhor não) - simplesmente como um “(...) primeiro passo, por assim dizer, para limpar a área, distanciar-se do universo social existente” (ZIZEK, 2011, p. 353). Ficar preso a essa primeira recusa do "não!" de Bartleby acabaria sendo, conforme sustentam Hardt \& Negri, um posicionamento marginal eminentemente suicida que, como bem expressam os autores,

Bartleby pode ser uma alma linda, mas por sua absoluta pureza agarra-se à borda de um abismo. Sua linha de fuga da autoridade é completamente solitária, e caminham continuamente à beira do suicídio. Em termos políticos, também, a recusa em si (do trabalho, da autoridade e da servidão voluntaria) leva apenas a uma espécie de suicídio social (MICHAEL; NEGRI, 2001, p. 224). 
Em poucas palavras, o Bartleby de Hardt \& Negri (2001) representa tão somente uma mera negação abstrata - ou uma simples negação -, sem com isso alcançar o efeito concreto do ato político enquanto tal. Para os autores, é necessário ainda um segundo momento: o momento em que essa negação abstrata deve ser superada “(...) pelo trabalho positivo e paciente da negação 'determinada' do universo social existente” (ZIZEK, 2011, p. 353).

O que passa ao largo das reflexões desses autores é que a recusa de Bartleby, longe de operar como uma simples denegação do estado de coisas estabelecido, já carrega em seu bojo o vazio absoluto sobre o qual a Lei é inscrita. De maneira específica, para Zizek, Bartleby figura muito mais que uma mera etapa do processo revolucionário: ele próprio já representa o ato revolucionário propriamente dito. Bartleby expressa a violência na sua forma mais fundamental: não a violência fascista cuja agitação especular de produzir alguma coisa nova a cada momento não serviu senão para manter tudo no seu devido lugar; mas uma espécie de violência absolutamente passiva que age efetivamente sobre as coordenadas elementares que configuram a ordem constituída. Aqui estão, pois, presente duas diferentes formas de se pensar a ação política: a primeira que eu qualifico de um ativismo conservador, isto é, o rebuliço constante que age unicamente para manter as coordenadas do sistema inalterado; e outra que consiste numa forma de revolução passiva, que, embora o estado de coisas permaneça aparentemente imperturbado, é ela que realiza uma transformação efetiva na estrutura formal da realidade. Podemos, pois, enquadrar o Bartleby de Zizek nesse segundo modelo, aquele que, por meio de sua indiferença inquietante no que concerne às exigências de sua função burocrática, produz a abertura de um vazio determinado, de um lugar puro, positivo, no âmago da própria Lei, e que, por isso mesmo, pode tocar na fragilidade inerente de toda ordem simbólica como tal. Trata-se fundamentalmente de uma negação determinada, ou aquilo que Hegel entendia por negação da negação. O que está contido no gesto puro de Bartleby, seu incompreensível preferiria melhor não, é antes a passagem de uma simples política da resistência, ou da contestação (política esta que, como vimos, desfruta daquilo que ela mesma nega) para um ato político propriamente dito: um ato que abre um novo espaço, totalmente exterior à posição hegemônica e à sua simples negação.

Nesse sentido, poderíamos imaginar Bartleby respondendo a uma série de propostas típicas do nosso mundo pós-moderno, que envolve, dentre inúmeras delas, as 
psicologias pop americanas de autoconhecimento e self-esteem; as ações ecológicas por um desenvolvimento sustentável; as lutas por minorias sexuais e, de um modo geral, todas as formas de resistência que encontramos hoje expressa na nossa insípida política de esquerda. E se no lugar da superficialidade expressa no entusiasmo daqueles que lutam por um mundo melhor - mas que simultaneamente negam em abdicar do gozo simbólico que desfrutam desse mesmo mundo - se no lugar disso, disséssemos, como Bartleby, preferiria melhor não? "Descubra a profundeza do seu verdadeiro eu, encontre a paz interior!" - "preferiria melhor não!", ou então, "você tem consciência do perigo que corre nosso meio ambiente?" "faça alguma coisa pela ecologia!" - "preferiria melhor não!" ou mesmo, "quantas injustiças raciais e sexuais nós podemos observar em torno de nós! não está na hora de fazer alguma coisa?" - "eu preferiria melhor não" (ZIZEK, 2007, p. 410).

Desta forma, Bartleby opera a subtração em toda sua pureza, “(...) a redução de todas as diferenças qualitativas a uma diferença mínima puramente formal" (ZIZEK, 2007, p. 410), que faz desmoronar todas as vacas sagradas do nosso campo ideológico. Porém, convém reforçar que não há nada de violento em sua afirmação, “(...) a violência resulta de seu ser impassível, insistente, inerte, imóvel" (Idem). "Bartlebly não poderia fazer mal nem mesmo a uma mosca" (Idem) - e é por isso mesmo que seu sorriso pueril é tão insuportável.

\section{Referências bibliográficas}

ADORNO, Theodor, W. Educação e emancipação. Rio de Janeiro: Paz e Terra, 1995.

DERRIDA, Jacques. O cartão-postal: De Sócrates a Freud e além. Rio de Janeiro: Civilização Brasileira, 2007.

FUKUYAMA, Francis. The end of history and the last man. New York: Free Press, 1992.

HARDT, Michael \& NEGRI, Antonio. Império. Rio de Janeiro: Record, 2001.

HUNTINGTON, Samuel, P. O choque de civilizações: e a recomposição da ordem mundial. Rio de Janeiro: Objetiva, 2010.

ZIZEK, Slavoj. O mais sublime dos histéricos: Hegel com Lacan. Rio de Janeiro: Jorge Zahar Editor, 1991.

Le spectre rôde toujours: actualité du Manifeste du Parti

Communiste. Paris: Nautilus, 2002.

\begin{tabular}{|l|l|l|l|l|}
\hline Revista Dialectus & Ano 1 & n. 1 & Julho-Dezembro 2012 & p. 219-229 \\
\hline
\end{tabular}


La parallaxe. Paris: Fayard, 2007.

. Em defesa das causas perdidas. São Paulo: Boitempo, 2011. 